\title{
T2-mapping- influence of arrhythmia and heart rate: A phantom experiment
}

\author{
Marcel Prothmann ${ }^{*}$, Matthias A Dieringer, Jeanette Schulz-Menger \\ From 19th Annual SCMR Scientific Sessions \\ Los Angeles, CA, USA. 27-30 January 2016
}

\section{Background}

Myocardial tissue differentiation applying Cardiovascular magnetic resonance (CMR) offers the capability to detect myocardial injury already in preserved ejection fraction. Detection of edema is a unique capability of CMR. Conventional T2 imaging suffers from technical challenges related to diseases specific issues like tachycardia, atrial fibrillation and pericardial effusion. T2-mapping seems to be more stable based on visual assessment. Little is known about its dependency of disease relate abnormalities. We aimed to investigate on the influence of heart rhythm abnormalities on T2 mapping.

\section{Methods}

We performed phantom experiments using a 1.5 Tesla Siemen Avanto Fit (Siemens Healthcare, Erlangen, Germany) equipped with a 32-channel cardiac coil. The T2 phantom consisted of five tubes (figure 1A). They were filled with different concentrations of manganese(II) chloride, to achieve various T2-times (60-80 ms). Tube 1 was set to $65 \mathrm{~ms}$, tube $2(70 \mathrm{~ms})$, tube $3(60 \mathrm{~ms})$, tube $3(80 \mathrm{~ms})$ and tube 4 (control tube $65 \mathrm{~ms}$ ) and the solution around the tubes ("blood" $=150 \mathrm{~ms}$ ). The phantom was surrounded by two $\mathrm{NISO}_{4}+\mathrm{NaCL}$ doped water bottles to achieve enough load for MRI. We applied a T2 prepared SSFP- based T2 mapping technique with the following parameters: voxel size: $1.6 \times 1.6$ $\times 6 \mathrm{~mm}^{3}$, TR $2.7 \mathrm{~ms}$, flip angle $70^{\circ}$, TE $1,15 \mathrm{~ms}$; GRAPPA reduction factor 2. Sinus rhythm heart rates of 60, 80,100 and $120 \mathrm{bpm}$ were simulated using an ECG simulator (Siemens Healthcare). Arrhythmia was simulated using a commercial ECG simulation device (ES 300 , SPI electronics). To assess repeatability of the T2 times, the T2 maps were acquired 6 times for each heart rate and rhythm. T2 times were quantified based
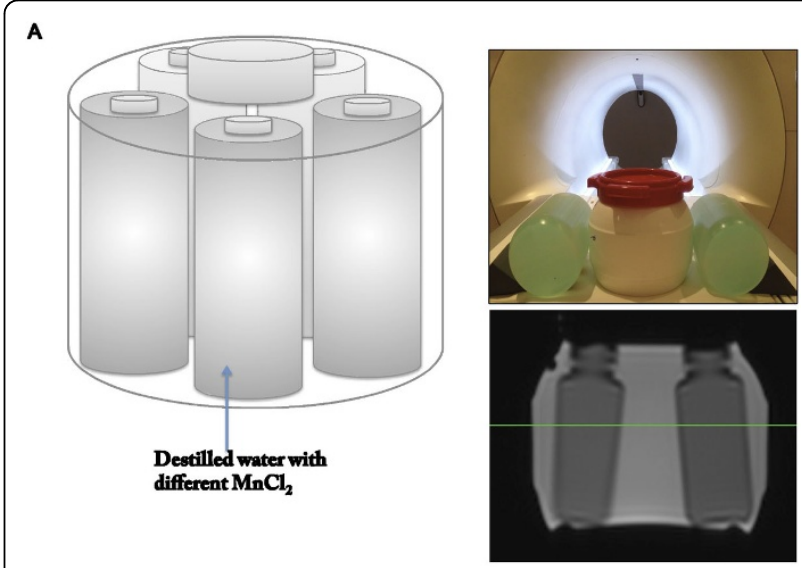

B

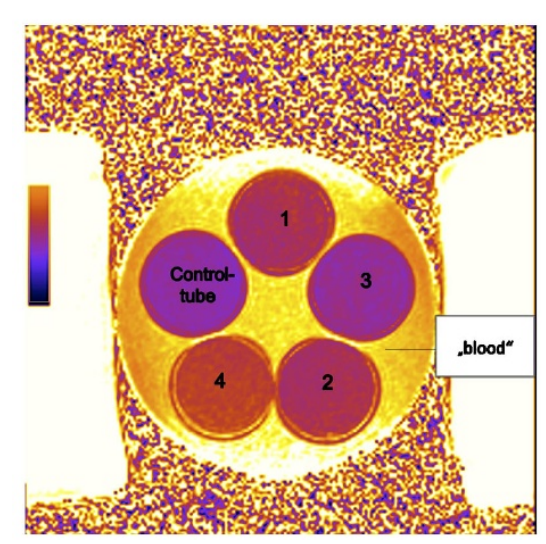

Figure $1 \mathrm{~A}$ - shows the construction of the T2 phantom B T2map Phantom. Each tube provides different T2-time.

on the inline T2 maps by drawing a ROI covering the entire phantom intersection using cvi42 5.0 (Circle Cardiovascular Imaging Calgary,Canada). 
Table 1 Mean T2-times (ms) depending on heart rate and rhythm

\begin{tabular}{cccccc}
\hline Heart rate bpm & SR $\mathbf{6 0}$ & SR $\mathbf{8 0}$ & SR 100 & SR 120 & Afib 120 \\
\hline Tube1 & $64.9 \pm 0.6$ & $63.9 \pm 0.7$ & $63.9 \pm 0.9$ & $64.5 \pm 1.0$ & $62.1 \pm 2.8$ \\
Tube2 & $70.8 \pm 0.97$ & $70.7 \pm 0.8$ & $70.7 \pm 0.8$ & $70.9 \pm 0.8$ & $70.3 \pm 0.5$ \\
Tube3 & $61.6 \pm 0,98$ & $61.4 \pm 1.1$ & $61.4 \pm 1.1$ & $60.8 \pm 0.9$ & $61.5 \pm 1.3$ \\
Tube4 & $82.6 \pm 1.57$ & $81.6 \pm 0.8$ & $81.6 \pm 0.8$ & $81.5 \pm 1.3$ & $81.7 \pm 3.2$ \\
"blood।" & $158.5 \pm 2.06$ & $156.8 \pm 3.0$ & $156.8 \pm 3$. & $158.1 \pm 3.2$ & $158.2 \pm 2.9$ \\
\hline
\end{tabular}

\section{Results}

T2 times were evaluable in all settings. T2 times did not show significant differences depending on heart rate variability within each tube (tube $1 \mathrm{p}=0.541$; tube $2 \mathrm{p}=0.661$; tube3 $\mathrm{p}=0.51$; tube4 $\mathrm{p}=0.813$; tube $5 \mathrm{p}=0.729$ ). Details are given in table 1 . Figure $1 \mathrm{~B}$ shows the $\mathrm{T} 2$ phantom using a simulated sinus rhythm at $60 \mathrm{bpm}$.

\section{Conclusions}

The influence of heart rhythm abnormalities and heart rate on T2-times seems to be not relevant. That gives the possibility to identify myocardial edema also in patients with arrhythmia. Further patient studies are needed.

Published: 27 January 2016

doi:10.1186/1532-429X-18-S1-W36

Cite this article as: Prothmann et al:: T2-mapping- influence of arrhythmia and heart rate: A phantom experiment. Journal of Cardiovascular Magnetic Resonance 2016 18(Suppl 1):W36.

Submit your next manuscript to BioMed Central and take full advantage of:

- Convenient online submission

- Thorough peer review

- No space constraints or color figure charges

- Immediate publication on acceptance

- Inclusion in PubMed, CAS, Scopus and Google Scholar

- Research which is freely available for redistribution

Submit your manuscript at www.biomedcentral.com/submit
C Biomed Central 